\title{
Kornual Gebelikte İki Olguda İki Tedavi Yöntemi
} İki Vakada Kornual Gebelik

\section{Two Treatment Methods in Two Cases of Cornual Pregnancy Cornual Pregnancy in Two Cases}

Ayhan Atıgan' ${ }^{1}$, Soner Gök ${ }^{1}$

'Pamukkale Üniversitesi Tıp Fakültesi Hastanesi, Kadın Hastalıkları ve Doğum Anabilim Dalı, Denizli, Türkiye
Iletişim: Ayhan Atıgan

Pamukkale Üniversitesi Tıp Fakültesi Hastanesi, Kadın Hastalıkları ve Doğum Anabilim Dalı, Denizli, Türkiye

e-mail: dratigan@hotmail.com

\section{ÖZET}

Gestasyonel kesenin uterin kavite dışına yerleşmesi olarak tanımlanan ektopik gebelik,erken gebelik döneminde yaşamı tehdit eden en sık görülen acil durumdur. Interstisyel ektopik gebelik,ektopik gelişen gebeliğin fallop tüpünün uterin bölümüne yerleşmesi olarak tanımlanır ve tüm ektopik gebeliklerin \%2-4 ünü oluşturur. Diğer tubal gebeliklere göre daha ileri gebelik haftalarında rüptür olur ve rüptür olduğunda genellikle aşırı kanama meydana gelir. Rüptüre interstisyel gebeliklerde maternal mortalite riski diğer tubal gebeliklere göre 2-5 kat fazladır. Interstisyel ektopik gebelikte erken tanı ve tedavi, rüptüre bağlı morbidite çok yüksek olduğundan dolayı çok önemlidir. Kornual gebeliğin yönetimine örnek gösterilebilecek nitelikte bir hastaya medikal, diğer hastaya cerrahi tedavi uygulanışı literatür eşliğinde incelendi.

Anahtar kelimeler: cerrahi tedavi, interstisyel ektopik gebelik, kornual gebelik, medikal tedavi

\section{SUMMARY}

Ectopic pregnancy, in which the gestational sac is outside the uterine cavity, is the most common life-threatening emergency in early pregnancy. Interstitial ectopic pregnancy defined as the ectopic gestation developing in the uterine part of the fallopian tube is rare, occuring in $2-4 \%$ of all ectopic pregnancies. It tends to rupture at a more advanced stage of gestation compared to tubal ectopic pregnancy; and when ruptured, hemorrhage is usually profound. The maternal mortality rate of ruptured interstitial pregnancy is 2-5 times higher than that of tubal ectopic pregnancy. Early diagnosis and treatment of interstitial ectopic pregnancy is particularly important because of the high morbidity associated with its rupture. As two examples of the management of cornual pregnancy; medical treatment was performed in one patient and surgical treatment was done in the other patient, both were examined in the light of literature.

Keywords: cornual pregnancy, interstitial ectopic pregnancy, medical treatment, surgical treatment 


\section{GíRiş}

Ektopik gebelik, insidansı gelişmiş ülkelerde artmakta olan gebeliğin ilk trimesterindeki en önemli mortalite ve morbidite nedenlerinden biridir (1). Ektopik gebeliklerin \%2-4 kadarını oluşturan interstisyel ektopik gebelik için mortalite oranı diğer ektopik gebeliklerin 2-5 katı kadardır (2). Ancak, erken tanı imkanı hastalığa bağlı mortalite ve morbiditeyi ciddi oranda azaltmıştır.

Kornual gebelik tanısı konulurken yapılan ultrasonografide boş uterus kavitesi ve gestasyonel kese etrafında ince myometriyal tabakanın bulunması önemlidir. Ayrıca renkli dopler ultrasonografide ateş halkası görüntüsü ile peritrofoblastik yoğun kanlanmanın gösterilmeside kornual gebelik tanısında önemlidir (3).

Bu süreçte hastalığın tedavisinde cerrahi tedaviden medikal tedaviye doğru bir geçiş olmuştur (4). Metotreksat ile medikal tedavi ilk defa Tanaka veark. tarafından 1982'de uygulanmıştır ve takip eden donemde medikal tedavi cerrahi ile ilgili riskler olmaksızın ektopik gebeliğin tedavisinde güvenilir ve etkin bulunmuştur (5). Tedavinin etkinliğine rağmen başarı oranları \%64,0 ile \%94,2 arasında değişmektedir.

En sık kullanılan medikal tedavi yöntemi Stovall ve ark. tarafından kullanılan tek doz intramuskuler (IM) metotreksat $50 \mathrm{mg} / \mathrm{m} 2$ verilmesidir(5). İlacın uygulanmasından sonra B-Human Chorionic Gonadotropin (B- hCG) seviyeleri rezolüsyon sağlanana kadar izlenir. Tedavi başarısızığını etkileyen faktörler olarak ß- hCG seviyelerinde belirgin yükseklik, fetal kardiyak aktivite varlığı, cul - de - sac' ta serbest sıvı varlığı ve ektopik gebelik çapının 3.5 cm'den büyük olması sayılır (6).

Bu çalışmada amacımı ektopik gebelikte tedavi seçeneği olarak metotreksatın etkinliğini ve seçili vakalarda cerrahinin önemini vurgulamaktır.

\section{OLGULARIN SUNUMU}

Olgu 1: Illk hastamız 27 yaşında obstetrik öyküsü gravida 5, parite 2,vajinal doğum 2, abortus 2 olan hasta acil servisten karın kasık ağrısı şikayetiyle başvurdu. Ek hastalık ve ilaç kullanım öyküsü yoktu. Hastanın ß- hCG değeri 6428 U/L idi. Yapılan transvajinal ultrasonografi'de sol kornual ektopik gebelik ve etrafında koagulum tespit edildi. Hastanın takibinde servise yatışından itibaren ağrılarının daha da artması alt kadranda defans ve hassasiyet mevcudiyeti ve tansiyon arteryel 85/50 mmHg, nabız 103/dk olması üzerine rüptüre ektopik gebelik tanısıyla laparotomi işlemine geçildi. Laparotomi esnasında kornual gebelik görüldü(Resim 1).
Hastaya ameliyata ek işlem olarak yapılan küretajın patoloji sonucunda intrauterin gebelik tespit edilmedi. Hastanın işlem sonrası günü ß- hCG değeri 6428 U/L'den 1140 U/L'a geriledi. Takiplerinde bhcg değerleri negatifleşti. Hastanın servise kabul edilişinde $14.4 \mathrm{~g} / \mathrm{dL}$ olan hemoglobin değeri peroperatif $12.3 \mathrm{~g} / \mathrm{dL}$ iken, post operatif dönemde 1.gün 11.9 g/dL, 11.gün poliklinik kontrolündeki değeri 14.3 g/dL idi.

Olgu 2: İkinci hastamı 30 yaşında obstetrik öyküsü gravida 3, parite 1, vajinal doğum 1, küretaj 1 olan hasta polikliniğe leke şeklinde kanama şikayetiyle başvurdu. Ek hastalık ve ilaç kullanımöyküsüyoktu. Hastanınß-hCG değeri 19726U/Liken yapılan transvajinal ultrasonografi'de $17^{*} 9 \mathrm{~mm}$ sol kornual ektopik gebelik lehine kese izlendi(Resim 3 a ve b). Kese içerisinde fetal pol oluşmuş olmasına karşın kardiyak aktivite izlenmedi. Hastaya onamları alındıktan sonra gerçekleştirilen küretaj işleminin patoloji sonucunda intrauterin gebelik izlenmedi. Hastaya sonrasında m2'ye 50 mg'dan tek doz Metotreksat intramuskuler uygulandı.Hastanın boyu (155 $\mathrm{cm}$ ) ve kilosu (55 kg) yardımıyla hesaplanan toplam yüzey alanı 1,5 m2 bulundu. Başka bir ifadeyle, hastaya toplam $75 \mathrm{mg}$ Metotreksat tek seferde uygulandı. Hastanın işlem sonrasındaki B-hcg değerleri sırasıyla; 2. gün $17496 \mathrm{U} / \mathrm{L}, 7$. gün $8379 \mathrm{U} / \mathrm{L}$, 14. gün $420 \mathrm{U} / \mathrm{L}, 21$.gün $54 \mathrm{U} / \mathrm{L}$, 30.gün 8 U/L tespit edildi. Doz tekrarı yapılmadan B- hCG değerlerinde gerileme izlenmiştir. Özellikle B- hCG değerinin 2.gün değeri ile 7.gün değeri arasında \% 15 üzerinde bir düşüş yaşanması tek doz uygulanan metotreksat tedavimizin başarılığı olduğunu göstermiştir. Hastanın bu süreçte hemoglobin değeri $12.4 \mathrm{~g} / \mathrm{dL}$ ten $12.1 \mathrm{~g} / \mathrm{dL}$ 'e geriledi.

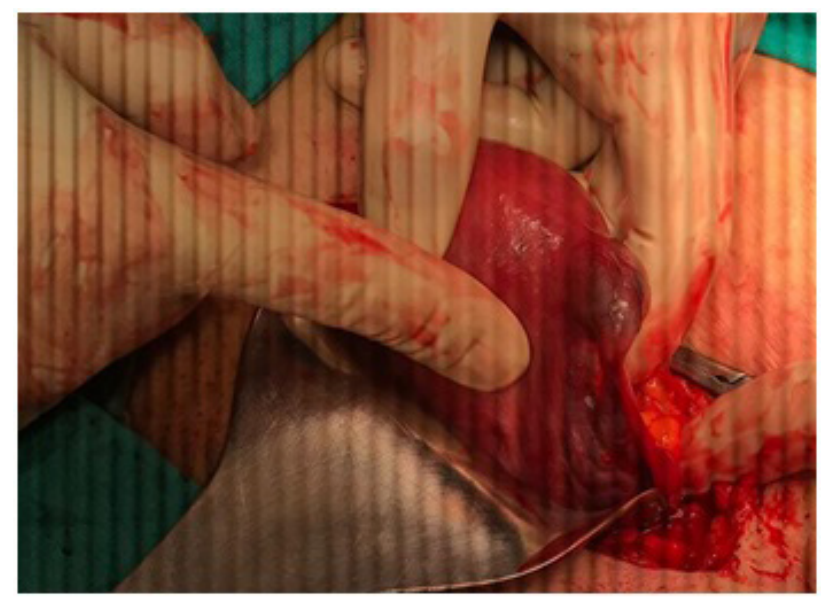

Resim 1: Laparotomi sırasında gözlenen sol kornual ektopik gebelik ve sol salpenks 


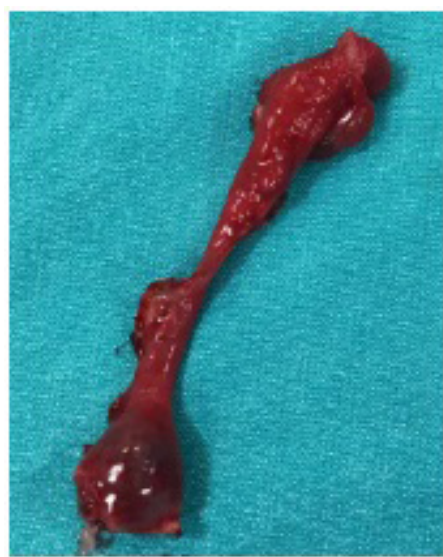

Resim 2: Ameliyat sonrası sol salpenjektomi materyali
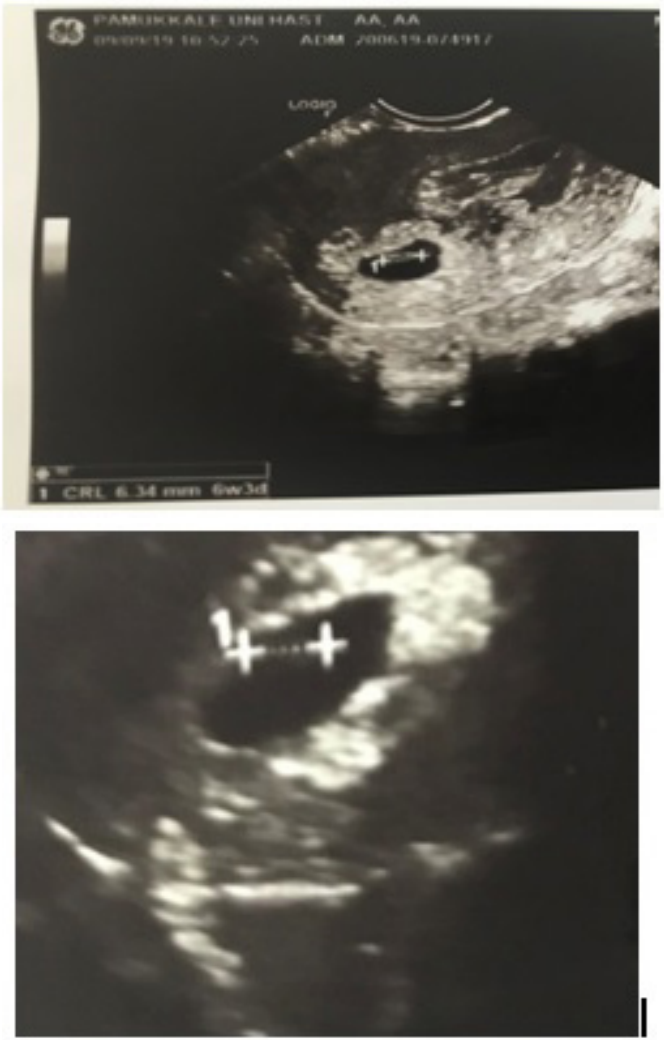

Resim 3 a ve b: Transvajinal ultrasonografi'de $17^{*} 9 \mathrm{~mm}$ sol kornual ektopik gebelik lehine kese izlendi

\section{TARTIŞMA}

Kornual gebelik tanısını koyarken ultrasonografi ve seri B- hCG takibinden yararlanılır. Timor-Tritsch ve ark.'larının ultrasonografi yardımıyla kornual gebelik tanısı koymak için tanımladıkları triad (boş uterus kavitesinin görülmesi, koryonik kesenin uterin kavitenin lateral kenarından $>1 \mathrm{~cm}$ ayrı olması ve gestasyonel sac etrafında ince miyometriyal tabakanın görülmesi) bugün halen güncelliğini korumaktadır (7). Her iki olgumuz da bu kriterleri taşımaktaydı.

Interstisyel ektopik gebelikte tedavi seçenekleri lokal veya sistemik metotreksat tedavisi, lokal potasyum klorid enjeksiyonu, konservatif laparoskopik cerrahi, uterin arter embolisi, kornual rezeksiyon veya gereğinde histerektomidir (8). Seçilecek tedavi yöntemi gestasyonel kesenin büyüklüğüne, hastanın fertilitesini koruma isteğine ve cerrahın deneyimine bağlıdır.

Rüptüre olmamış ektopik gebelik olgularının tedavisinde, tek doz metotreksat uygulamasının başarısında uygun olguların seçimi tedavinin anahtarıdır. Yayınlanan çalışmaların çoğunda, olgularda tedavi öncesi düşük B- hCG değerlerinin varlığı (çoğunlukla $<4000 \mathrm{IU} / \mathrm{ml}$ ), fetal kardiak aktivitenin olmaması ile ektopik gebelik kitlesinin küçük olması bu tedavinin başarısında uygun kriterler olduğu düşünülmüştür (6). Ancak, yüksek B- hCG değerlerinde hemodinamisi bozulmamış seçilmiş vakalarda cerrahi öncesi medikal tedavi olarak metotreksat tedavisi de akılda tutulmalıdır. Literatür incelendiğinde, B hCG değerinin yüksek olduğu durumlarda dahi öncelikle tek doz olmak üzere metotreksat'ın çoklu doz uygulamaları da başarıly uygulanmaktadır (3,9-11). Metotreksat tedavisi tek doz (50 $\mathrm{mg} / \mathrm{m} 2)$, ikili doz (1. ve $4 . g u ̈ n ~ 50 \mathrm{mg} / \mathrm{m} 2$ ) ve çoklu doz (1-3-5-7.günlerde 1 $\mathrm{mg} / \mathrm{kg}$ ) olmak üzere farklı protokollerle uygulanabilinir. Metotreksat uygulandıktan sonra 4. ve 7.günlerde B- hCG değerinde \%15'ten fazla düşüş beklenir. Eğer beklenen düşüş gerçekleşmez ise ikinci doz olarak metotreksat verilir. Bizim metotreksat uyguladığımız vakamızda B- hCG değeri $\% 15^{\prime}$ ten fazla gerilediği için ek doz yapılmasına intiyaç kalmamıştır. Takip eden B hCG serilerinde düşüş başarılı bir şekilde devam etti.

Interstisyel ektopik gebelik, ektopik gebeliklerin \% 2-4'ünün oluşturur. Diğer ektopik gebeliklere göre daha geç fark edildiğinden, ileri gebelik haftalarında rüptüre eğilimlidir. Rüptüre olduğu zaman hemoraji çok fazladır ve mortalite riski diğer tubal ektopik gebeliklerden 2-5 kat daha fazladır (2) . Bu hasta grubunda medikal tedaviyi denemek yerine cerrahi tedaviye geçmek daha iyi bir seçim olacaktır.

Ayırıı tanıda dikkat edilmesi gereken, angular gebelik ile karıştııımamasıdır. Angular gebelik nidasyonun uterin 
kavitenin uterotubal bileşke bölgesinin hemen medialinde gerçekleştiği durumdur ve bir ektopik gebelik türü sayılmaz. Konservatif yaklaşım tercih edilir. \%60 olguda viabl bir fetusun doğumuna kadar gebelik devam eder (12).

Sonuç olarak, interstisyel ektopik gebelikte rüptürden önce tanı koymak güç olmakla birlikte erken tanı, morbidite ve mortalite riskini azaltmak açısından çok önemlidir. Olgu 2 'de olduğu gibi rüptüre olmamış uygun ektopik gebelik olgularında tek doz sistemik metotreksat uygulamasının, ektopik gebeliğin medikal tedavisinde tedavi seçeneği olabileceği sonucuna varıldı. Ancak Olgu 1'deki gibi rüptüre ektopik gebelik tanılı hastalarda ve vitalleri stabil olmayan vakalarda acil cerrahi girişim gerekeceği de akılda tutulmalıdır. Özellikle, metotreksat tedavisinde B- hCG değerinin takibin yanı sıra çoklu dozlarda karaciğer toksisitesi açısından karaciğer enzimlerinin takibi de gereklidir. Cerrahi işlemlerde ise hemoglobin değerlerine dikkat edilmelidir. Ancak metotreksat uygulaması sonrasında da myometrial duvardaki zayıflamanın neden olabileceği uterin rüptür görülebilir. Metotreksat uygulamasının ve cerrahi işlemin getirebileceği yan etkilerin belirlenmesi için yakın klinik takip gerektiği unutulmamalıdır.

Çıkar iliş̧kisi: Yazarlar çıkar ilişkisi olmadığını beyan eder

\section{KAYNAKLAR}

1. Berg CJ, Chang J, Calloghan WM, Whitehead SJ. Pregnancy related mortality in the United States, 1991 - 1997. Obstet Gynecol 2003;101: 289-296.

2. Lau S, julandi T. Conservative medical and surgical management of interstitial ectopic pregnancy. Fertil Steril 1999; 72: 207-215.

3. Fisch JD, Ortiz B, Tazuke S, Chitkara U, Giudice L. Medical management of interstitial ectopic pregnancy: a case report and literature review. Hum Reprod 1998;13(7):1981-6. http://dx.doi.org/10.1093/humrep/13.7.1981

4. Luciano AA, Roy G, Solima E. Ectopic pregnancy from surgical emergency to medical management. Ann NY Acad Sci 2001;943: 235-254.

5. Tanaka T, Hayashi H, Fujimoto S, Ichinoe K. Treatment of interstitial

ectopic pregnancy with methotrexate: report of a successful case. Fertil Steril 1982;37(6): 851-852.

6. Yıldırım G, Güngördük K, Aktaş FN, Ülker $V$, Sudolmuş $S$, Tekirdağ Ai. Single dose methotrexate in treatment of ectopic pregnancy: Review of 85 cases. J Turk Soc Obstet Gynecol 2007;4(1): 68-71.

7. Timor-Tritsch IE, Monteagudo A, Matera C, Veit CR. Sonographic evolution of cornual pregnancies treated without surgery. Obstet Gynecol 1992;79:1044-9. pregnancy: A rare and difficult clinicosonographic diagnosis. J Hum Reprod Sci 2008; 1: 81-82. http://dx.doi. org/10.4103/0974-1208.44116

9. Dilbaz S, Katas B, Demir B, Dilbaz B. Treating cornual pregnancy with a single methotrexate injection: a report of 3 cases. J Reprod Med 2005;50:141-4.

10. Balsak $D$, İnal $M$, Yıldıım Y, Öner RS, Tınar Ş. Rüptüre olmamış ektopik gebeliğin intravenöz metotreksat ile başarlı tedavisi:iki olgu sunumu. İnönü Ünviversitesi Tıp Fakültesi Dergisi 2007;14(1):65-7

11. Jermy K, Thomas J, Doo A, Bourne T. The conservative management of interstitial pregnancy. BJOG 2004;111:12838. http://dx.doi.org/10.1111/j.1471-0528.2004.00442.x 12. Ateşalp F, Erhan G, Bozkurt S, Köten M. Bir olgu nedeniyle interstisyel gebelik. ist Tip Fak Derg 1996;4: 43-46. 